\title{
PENGEMBANGAN MULTIMEDIA INTERAKTIF MATERI PERUBAHAN WUJUD BENDA BAGI SISWA SEKOLAH DASAR
}

\author{
Mila Fitri Nuraini, Susilaningsih, Agus Wedi \\ Jurusan Teknologi Pendidikan, Fakultas Ilmu Pendidikan, Universitas Negeri Malang \\ Jalan Semarang 5 Malang 65145 0341-574700 \\ Milafitri144@gmail.com \\ Article History \\ Received:26 Juni 2020, Accepted: 31 Agustus 2020, Published: 26 Februari 2021
}

\begin{abstract}
Abstrak
Multimedia interaktif adalah kombinasi lebih dari satu jenis media yang kemudian disatukan sehingga dapat digunakan untuk menyampaikan informasi pembelajaran berupa materi pelajaran. Penelitian ini memiliki tujuan menghasilkan suatu multimedia interaktif yang layak digunakan untuk kegiatan belajar mengajar materi perubahan wujud benda ditingkat sekolah dasar. Metode yang digunakan dalam penelitian menggunakan model pengembangan Lee \& Owens. Review produk multimedia interaktif dilaksanakan oleh ahli media dan ahli materi. Uji coba produk dilaksanakan oleh 16 orang siswa kelas V SDN Bareng 4 Malang. Hasil review produk mendapat tanggapan positif dan memperoleh kategori layak digunakan sebagai sumber belajar.
\end{abstract}

Keyword: Pengembangan; Multimedia Interaktif; Perubahan Wujud Benda.

\begin{abstract}
Interactive multimedia is a combination of more than one type of media which is then put together so that it can be used to convey learning information in the form of subject matter. This study has the aim of producing an interactive multimedia suitable for teaching and learning activities in material transformation of objects at the elementary school level. The method used in the study used the Lee \& Owens development model. Interactive multimedia product reviews are carried out by media experts and material experts. The product trial was carried out by 16 students of class V SDN Bareng 4 Malang. The results of product reviews received positive responses and obtained a category worthy of use as a learning resource.
\end{abstract}

Keyword: Development; Interactive Multimedia. 


\section{PENDAHULUAN}

Proses interaksi antara siswa, guru dan sumber belajar dalam suatu lingkungan belajar disebut dengan pembelajaran. Semakin beragamnya sumber belajar merupakan satu langkah yang baik dari perkembangan IPTEK (Praherdiono, 2008). Pembelajaran sebagai suatu susunan terdiri atas unsur-unsur yaitu tujuan pembelajaran, materi, metode pembelajaran, sumber belajar, dan kegiatan belajar mengajar serta evaluasi (Setyosari \& Sihkabuden, 2005). Dalam pembelajaran di kelas tidak sedikit siswa masih merasa kesulitan memahami dan menerapkan materi yang disampaikan oleh guru, dikarenakan siswa usia SD sulit memahami sesuatu yang bersifat abstrak, sehingga dibutuhkan objek konkret berupa sumber belajar yang digunakan untuk pembelajaran.

Media dijadikan perantara karena berfungsi sebagai penyampai pesan. Media merupakan usaha untuk menstimulus pikiran, perhatian, perasaan, dan minat siswa agar terjadi proses belajar melalui perantara dari yang mengirim informasi kepada yang menerima (Sadiman, 2009). Berbagai media diantaranya buku, gambar, dan video dapat membantu kegiatan belajar mengajar. Sumber belajar dapat mendukung keberhasilan suatu pembelajaran serta mampu meningkatkan keberhasilan belajar siswa (Ramadhani, dkk., 2019). Namun masih banyak yang hanya terpusat pada buku saja sehingga pembelajaran cenderung membosankan dan siswa merasa tidak tertarik.

Multimedia interaktif merupakan sumber belajar dengan bantuan komputer untuk menunjang pembelajaran. Komputer merupakan sumber belajar yang bisa menampilkan hasil siswa setelah belajar (Rachmadtullah \& Sumantri, 2018). Multimedia mampu menyajikan kombinasi antara teks, gambar, audio dan video. Multimedia interaktif adalah sumber belajar yang bisa digunakan oleh pengguna secara individu melalui alat kontrol (Daryanto, 2010). Selain pada komputer, multimedia interaktif juga digunakan dalam smartphone atau android. Siswa bisa belajar sendiri karena siswa leluasa untuk mengoperasikan multimedia (Ramadhani \& Muhtadi, 2018).

Berdasarkan informasi yang diperoleh dari guru di SDN Bareng 4 Malang, sekolah sudah memiliki fasilitas cukup seperti sudah tersedianya LCD proyektor untuk sumber belajar elektronik. Sehingga sekolah sudah mampu melaksanakan kegiatan belajar mengajar berbantuan multimedia interaktif. Akan tetapi, kegiatan belajar mengajar berbantuan multimedia masih jarang dilakukan di sekolah ini, ditambah lagi dengan kemampuan guru bisa dibilang kurang pada IT khususnya dalam pembuatan media elektronik. Tanggapan dari guru setelah diperlihatkan bentuk multimedia interaktif menunjukkan ketertarikan untuk memakainya dalam kegiatan belajar mengajar. Begitu pula siswa juga menunjukan ketertarikan terhadap pemakaian multimedia interaktif di kelas.

Berdasarkan tanya jawab terhadap guru kelas di SDN Bareng 4 Malang, kemampuan tiap anak untuk memahami pembelajaran selalu berbeda beda. Namun terdapat beberapa materi masih sulit dipahami oleh keseluruhan siswa seperti materi perubahan wujud benda. Sehingga memerlukan media agar materi dapat tersampaikan dan bisa dipahami siswa. Dalam penyampaian materi ruang lingkup ilmu pengetahuan memerlukan gambaran asli atau seperti simulasi agar mempermudah siswa memahami materi. Melihat permasalahan tersebut diperoleh kesimpulan mengembangkan multimedia interaktif dengan materi perubahan wujud benda bagi siswa kelas V sekolah dasar.

Multimedia interaktif menampilkan materi dengan efisien, dan menarik minat siswa serta meningkatkan kemampuan siswa dalam memecahkan masalah (Syawaludin, dkk., 2019). Multimedia ini akan disertai gambar, teks, audio dan video. Multimedia dirancang dengan cakupan materi, evaluasi, pengayaan dan remedial untuk siswa. Selain dari hasil tanya jawab terhadap siswa dan guru, adapun beberapa penelitian yang relevan dijadikan acuan pada penelitian ini yaitu penelitian oleh Fanny (2013) yaitu mengembangkan multimedia interaktif bagi siswa sekolah dasar dan produknya mendapat tanggapan positif. Kemudian penelitian oleh Illahi (2018) yang juga mengembangkan suatu sumber belajar dan mendapatkan kategori layak. Serta penelitian oleh Rosita (2015) dengan mengembangkan 
multimedia interaktif juga memperoleh kategori layak. Berdasarkan ketiga penelitian diatas diperoleh kesimpulan bahwa multimedia interaktif dapat digunakan sebagai sumber belajar yang layak digunakan untuk kegiatan belajar mengajar.

Produk yang dihasilkan dalam penelitian ini berupa multimedia interaktif materi perubahan wujud benda. Selain itu, penyajian materi juga lebih detail, karena didalam produk terdapat komponen berupa gambar, audio dan video sebagai pendukung penyampaian materi dengan teks. Serta terdapat tombol navigasi untuk menjadi alat kontrol multimedia. Sehingga nantinya produk ini mampu membuat siswa tertarik serta mampu memotivasi agar siswa lebih giat belajar. Multimedia interaktif materi perubahan wujud benda ini dapat dijadikan alternatif solusi bagi permasalahan yang terjadi di SDN Bareng 4 Malang.

\section{METODE}

Pengembangan multimedia interaktif ini, menggunakan model yang diadopsi oleh Lee dan Owens (2004). Pemilihan model ini dikarenakan model memiliki tahapan yang rinci dan tepat digunakan dalam mengembangkan multimedia. Terdapat lima tahapan dalam model tersebut, yaitu 1) Assesment/analysis terdiri dari 2 bagian yaitu analisis kebutuhan kemudian analisis awal \& akhir; 2) Desain (Design); 3) Pengembangan (Development); 4) Implementasi (Implementation); 5) Evaluasi (Evaluation). Namun dikarenakan beberapa faktor, pengembangan ini hanya menggunakan 3 tahapan saja yaitu mulai tahapan analisis, tahap desain, dan tahap pengembangan.

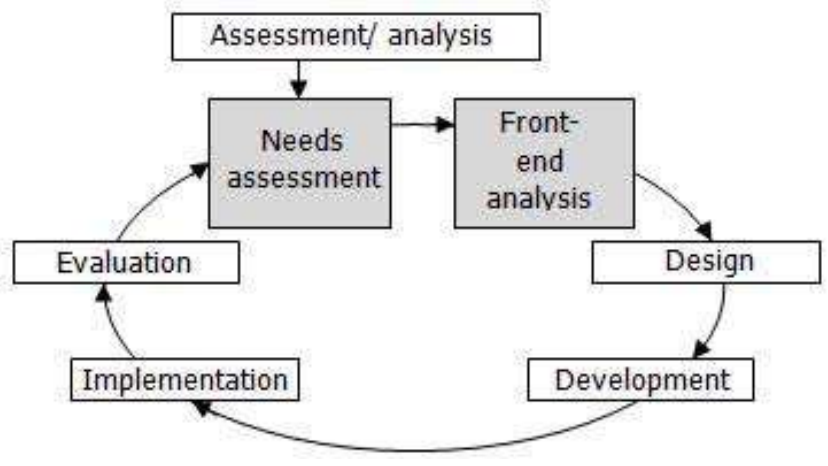

\section{Gambar 1. Model Pengembangan William W.Lee dan Diana L. Owens (2004)}

Subjek penelitian pengembangan ini adalah ahli mediadan ahli materi serta siswa kelas V SDN Bareng 4 Malang. Review multimedia interaktif ini dilakukan oleh ahli materi dan ahli media. Kemudian setelah dikatakan layak, selanjutnya produk diuji cobakan kepada siswa. Tahap uji coba dilakukan dalam dua tahap yaitu uji coba skala kecil yang melibatkan 3 siswa yang dipilih secara acak dan uji coba skala besar yang melibatkan seluruh siswa kelas V SDN Bareng 4 Malang sejumlah 16 siswa.

Teknik pengumpulan data penelitian menggunakan instrumen berupa angket. Terdapat 3 angket yang digunakan untuk memberikan penilaian terhadap multimedia interaktif yaitu angket ahli media, ahli materi dan angket untuk siswa. Data yang digunakan dalam penelitian meliputi data kuantitatif dan kualitatif. Teknik analisis data menggunakan teknik analisis data kuantitatif dan kualitatif.

\section{HASIL}

\section{Need Assesment}

Need Assesment dilakukan dengan observasi dan wawancara kepada guru dan siswa di SDN Bareng 4 Malang. Tujuannya adalah untuk mengetahui masalah di sekolah tersebut sehingga arah pengembangan dapat ditentukan. Multimedia interaktif ini diperlukan untuk membantu pembelajaran karena terkait permasalahan di sekolah yaitu siswa cenderung bosan dan kurang tertarik jika hanya belajar menggunakan buku. 


\section{Front-end Analysis}

Tahapan ini bertujuan untuk mendapatkan informasi secara detail tentang produk/media. Kegiatan ditahap ini yaitu analisis terhadap karakteristik siswa, situasi dan kondisi serta ketersediaan sarana prasarana di SDN Bareng 4 Malang. Hal ini dimaksudkan untuk mengetahui gambaran terkait pelaksanaan kegiatan selanjutnya. Sehingga tujuan pembelajaran bisa ditentukan serta dapat memperkecil hambatan saat mengimplementasikan produk/media.

\section{Design}

Kegiatan pada tahap desain yaitu melakukan perencanaan dalam mengembangkan produk multimedia interaktif. Pada halaman utama produk/media terdapat petunjuk penggunaan, tujuan pembelajaran, materi, evaluasi atau soal-soal, dan informasi. Materi yang disajikan kebanyakan berupa video mengenai perubahan wujud benda disesuaikan dengan pemilihan materi untuk dikembangkan dalam produk. Terdapat pula soal evaluasi dimana setelah mengerjakannya, siswa bisa melihat langsung nilai yang mereka dapatkan sebagai feedback setelah menjawab soal evaluasi.

\section{Development}

Software yang digunakan untuk mengembangakan produk adalah Articulate Storyline 3 sebagai penyusun multimedia, Adobe Illustrator dan Microsoft Power Point untuk memproses gambar serta menggunakan Audacity untuk memproses audio. Setelah produk selesai dibuat, kemudian tahap berikutnya adalah tahap review dan uji coba oleh subyek penelitian.

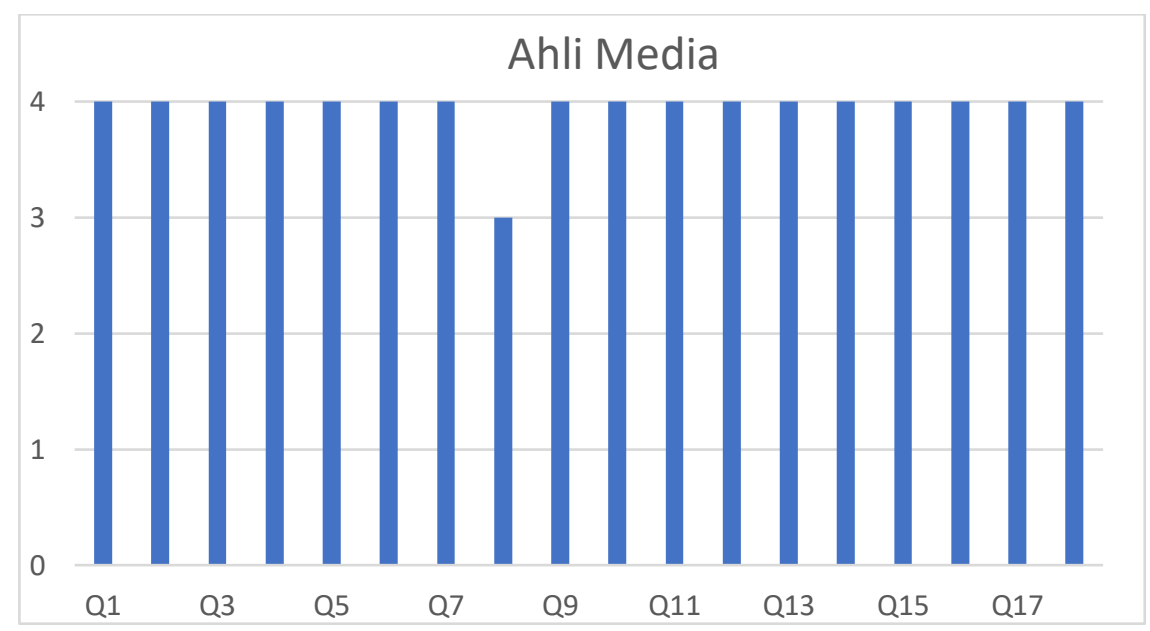

Gambar 2. Hasil Review Ahli Media

Penilaian hasil review ahli diperoleh dari ahli media untuk mengetahui kelayakan produk dan ahli materi untuk mengetahui kelayakan materi didalamnya. Hasil review terhadap ahli media dan ahli materi ditampilkan pada gambar 2.

Hasil review ahli media mendapatkan rerata nilai sebesar 3,94 dari 4,00. Dari seluruh pertanyaan terdapat 17 pernyataan dengan nilai 4 , dan 1 pernyataan dengan nilai 3 seperti yang terlihat pada gambar 2. Sehingga produk hasil kembangan dinyatakan layak untuk digunakan. Ahli media memberikan komentar bahwa keseluruhan multimedia interaktif sudah bagus.

Hasil review ahli materi mendapatkan rerata nilaisebesar 3,44 dari 4,00. Dari seluruh pertanyaan terdapat 8 pernyataan dengan nilai 4, dan 10 pernyataan dengan nilai 3 seperti pada gambar 3 . Sehingga produk hasil kembangan dinyatakan layak untuk digunakan. Ahli materi memberikan komentar multimedia interaktif sudah bagus dan materi telah sesuai. 


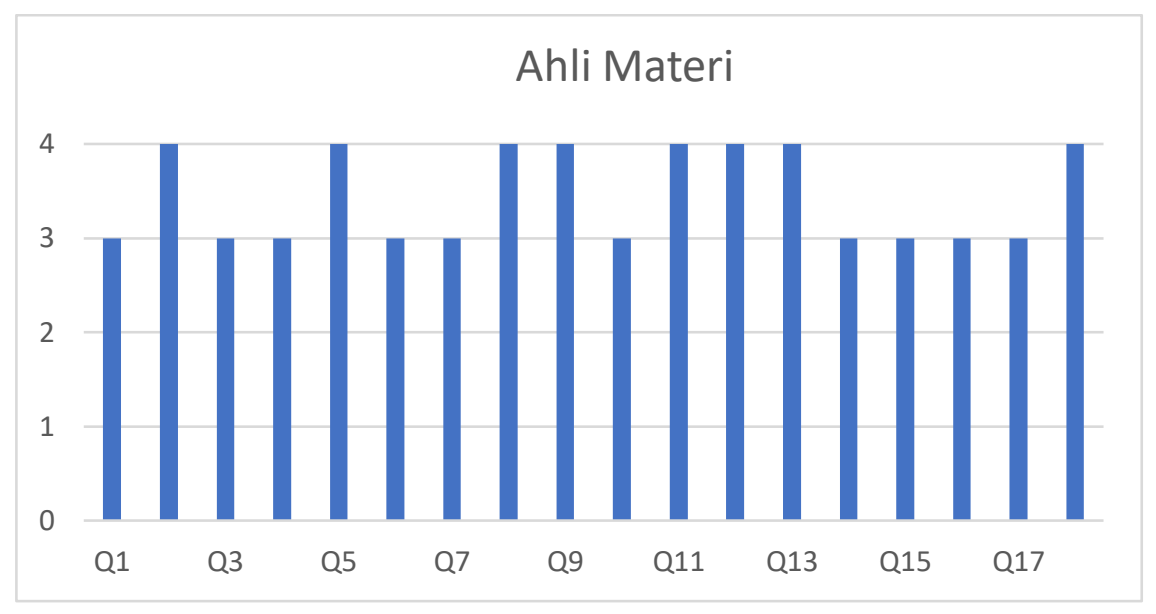

Gambar 3. Hasil Review Ahli Materi

Uji coba produk melibatkan 16 siswa kelas V SDN Bareng 4 Malang. Hasil dari angket respon siswa mendapatkan rerata nilai sebesar 3,64 dari 4,00. Beberapa siswa menyampaikan pendapatnya bahwa multimedia interaktif sudah bagus, materi dan evaluasi sudah jelas.

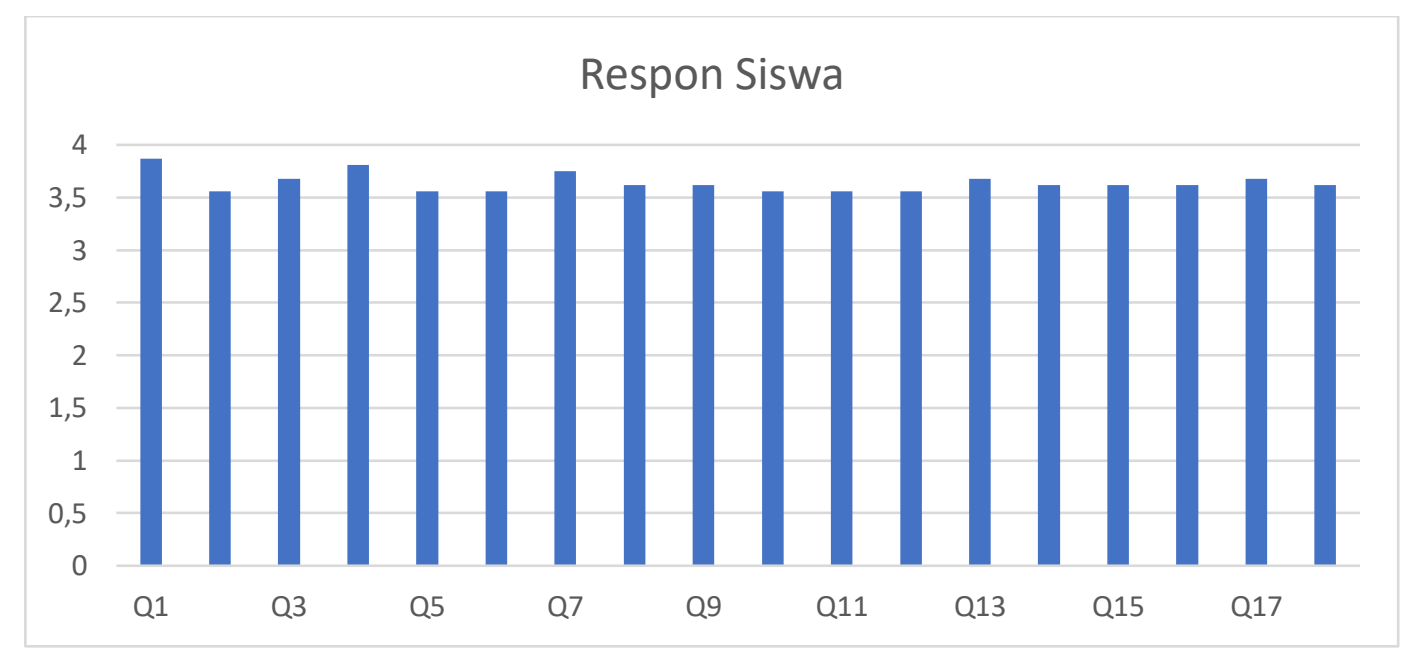

Gambar 4. Hasil Respons Siswa

\section{PEMBAHASAN}

Multimedia interaktif materi perubahan wujud benda ini sudah melalui review oleh ahli media, ahli materi dan telah mendapatkan tanggapan siswa. Hasil review ahli media mendapatkan nilai total 3,94 dan mendapatkan respons positif dengan 17 pernyataan mendapatkan nilai 4 kemudian 1 pernyataan mendapatkan nilai 3. Q8 tentang pemilihan jenis huruf (font) sudah sesuai untuk siswa kelas V mendapatkan nilai 3. Hal ini dikarenakan jenis huruf yang dipilih hanya sejenis saja namun sudah sesuai untuk anak usia kelas V. Ahli media juga menyampaikan bahwa keseluruhan produk sudah bagus dan dapat digunakan. Hasil review ahli media keseluruhan mendapatkan respons positif dan dinyatakan layak digunakan tanpa revisi.

Kemudian hasil review ahli materi juga mendapatkan nilai tinggi yaitu sebesar 3,44. Terdapat 8 pernyataan yang mendapatkan nilai 4 dan 10 pernyataan mendapatkan nilai 3. Q1, Q3, Q4 tentang kompetensi dasar dan $\mathrm{j}$ indikator sudah sesuai dengan kurikulum yang berlaku. Q6 dan Q7 tentang penyajian materi sudah sesuai runtutan materi. Q10 tentang penyajian video sudah sesuai materi. Q14, Q15, Q16, Q17 tentang petunjuk pengerjaan soal, bahasa dalam soal evaluasi dan pencapaian tujuan pembelajaran juga sudah sesuai. Ahli materi juga menyampaikan bahwa produk sudah bagus dan sudah sesuai materi dan medianya. Hasil dari review ahli materi mendapatkan respons positif dan dinyatakan layak digunakan tanpa revisi. 
Hasil uji coba produk mendapatkan tanggapan dari sebanyak 16 siswa. Dengan tiap-tiap pernyataan pada angket secara keseluruhan rata-rata mendapatkan nilai 4 dan 3 . Hal ini menandakan siswa tertarik untuk belajar dengan multimedia interaktif. Kemudian dari beberapa audiens atau siswa menyampaikan belajar menjadi lebih jelas, kemudian soal yang disajikan sangat jelas. Setelah membaca materi sajian siswa juga berhasil menyelesaikan soal-soal evaluasi yang juga disajikan dan mendapatkan hasil cukup baik. Materi perubahan wujud benda erat kaitannya dengan kegiatan sehari hari yang sering dijumpai disekitar kita. Siswa diarahkan untuk terlibat langsung dengan lingkungan sekitar dengan melihat, merasa, membau dan mendengar atau menggunakan seluruh panca indera agar belajar menjadi bermakna (Nurul \& Maris, 2000).

Kegiatan belajar dapat menjadi lebih baik apabila menggunakan multimedia (Aloraini, 2012). Dengan tampilan menarik serta penggunaan dapat secara mandiri, multimedia secara tidak langsung dapat menambah minat belajar (Munadi, 2012). Pembelajaran dengan multimedia interaktif terbukti lebih unggul daripada media konvensional saja (Rachmadtullah, dkk., 2019). Multimedia dapat menciptakan pembelajaran yang mudah dan fleksibel (Malik \& Agarwal, 2012). Multimedia interaktif dikembangkan sebagai alternatif untuk memfasilitasi cara belajar dan mengatasi perbedaan kecepatan belajar tiap siswa (Akbar, 2016). Hadirnya multimedia dapat mengakomodir modalitas perbedaan belajar siswa, membuat belajar jadi menyenangkan dan tidak monoton (Kuncahyono, 2018). Anak usia SD masih cenderung suka untuk bermain, maka dengan multimedia interaktif kegiatan siswa akan menyenangkan sehingga siswa mendapatkan kenyamanan dalam kegiatan belajar (Susilo, 2017).

Mengembangkan multimedia sendiri dapat berkontribusi untuk menjadi solusi masalah pembelajaran sehingga penggunaannya dapat meningkatkan pembelajaran (Babiker, 2015). Perubahan peran pendidikan saat ini diperkuat dengan teknologi multimedia dan hal ini membawa pandangan baru terhadap pendidikan dan evolusi konsep pengembangan konten inovatif yang dapat dikomunikasikan kepada pelajar (Almara'beh, dkk., 2015). Media berperan penting bagi kegiatan belajar, dengan teknologi yang berkembang maka mediapun mengalami perkembangan juga(Saifudin, 2020). Siswa dapat belajar secara mandiri karena multimedia interaktif merupakan media pembelajaran yang bersifat individual (Arief, 2018).

Multimedia interaktif merupakan suatu program berbantuan komputer sehingga memungkinkan penggunannya dapat mengontrol sendiri dan merespon segala permintaan tersebut (Utami, 2016). Dalam perkembangannya, komputer memberi pengaruh cukup kuat di setiap bidang contohnya pendidikan yaitu kegiatan belajar mengajar (Yusuf, 2017). Selain komputer, android atau smartphone juga memiliki pengaruh dalam berbagai bidang. Contohnya adalah pendidikan, karena android bisa untuk mengakses laman-laman referensi yang beraneka ragam. Multimedia interaktif selain bisa diakses dengan komputer maupun laptop juga bisa diakses melalui android atau smartphone.

Materi perubahan wujud benda sendiri tergolong dalam ruang lingkup Ilmu Pengetahuan Alam. Siswa terkadang menemui kesulitan ketika menjumpai materi abstrak seperti ilmu pengetahuan alam, karena sumber belajar yang dipakai hanya gambar jadi masih sulit dipahami siswa (Saputri, dkk., 2018). Materi pelajaran IPA memuat materi tentang fenomena dan pengetahuan alam sehingga pembelajaran IPA penting untuk dimengerti siswa (Hana, 2016). Penyajian materi harus sesuai tujuan dalam kurikulum. Jadi tidak disarankan menyediakan bahan belajar diluar tujuannya (Martin, dkk., 2013). Karena hal ini membuat belajar tidak fokus pada pencapaian tujuan yang ditentukan. Kelengkapan komponen pembelajaran merupakan salah satu hal penting dalam pencapaian tujuan. Siswa memerlukan sumber belajar yang bisa mereka pakai untuk mempelajari materi tanpa bantuan guru (Prayogo, 2015).

Multimedia interaktif materi perubahan wujud benda ini memperoleh kategori layak untuk digunakan dalam proses pembelajaran serta mampu meningkatkan minat siswa dalam belajar. Multimedia interaktif ini mempermudah guru saat menyajikan materi, dan pemahaman siswa juga lebih meningkat. Pada multimedia interaktif terdapat materi dengan contoh-contoh yang berkaitan dengan 
kegiatan sehari-hari agar siswa mudah memahaminya. Selain materi, juga disediakan soal evaluasi untuk mengukur tingkat keberhasilan siswa setelah membaca materi. Multimedia interaktif ini dapat dipakai di komputer, laptop ataupun android.

\section{SIMPULAN}

Multimedia interaktif ini merupakan inovasi untuk membantu proses pembelajaran sehingga menjadi kreatif karena desain didalamnya. Multimedia interaktif mampu meningkatkan minat belajar siswa serta pemahaman siswa terhadap suatu materi dapat meningkat. Selain itu multimedia interaktif ini bisa digunakan dengan android ataupun laptop dan komputer. Seperti pada penelitian-penelitian sebelumnya juga menghasilkan multimedia interaktif juga mendapat tanggapan positif dan mendapatkan kategori layak. Hasil review multimedia interaktif materi perubahan wujud benda dilakukan oleh ahli media, ahli materi dan tanggapan dari siswa, dan diperoleh kesimpulan multimedia interaktif mendapatkan tanggapan positif dan mendapatkan kategori layak digunakan untuk pembelajaran.

\section{DAFTAR RUJUKAN}

Akbar, T. N. (2016). Pengembangan Multimedia Interaktif IPA Berorientasi Guided Inquiry Pada Materi Sistem Pernapasan Manusia Kelas V SDN Kebonsari 3 Malang. Jurnal Pendidikan, 1(6), 1120-1126.

Almara'beh, H., Amer, E., \& Sulleman, A. (2015). The Effectiveness of Multimedia Learning Tools in Education. International Journal of Advanced Research in Computer Science and Software Engineering, 5(12), 761-764.

Aloraini, S. (2012). The Impact of Using Multimedia on Students' Academic Achievement in the College of Education at King Saud University. journal of King Saud University - Languages and Translation, 75-82.

Arief, L. (2018). Pengembangan Multimedia Interaktif Mata Pelajaran IPA Pokok Bahasan SIstem Peredaran Darah Manusia untuk Kelas VIII SMP Wahid Hasyim Malang. Jurnal Kurikulum Teknologi Pendidikan, 1(3), 257-263.

Babiker, M. E. (2015). For Effective Use of Multimedia in Education, Teachers Must Develop their Own Educational Multimedia Applications. TOJET: The Turkish Online Journal of Educational Technology, 14(4), 62-68.

Daryanto. (2010). Media Pembelajaran. Yogyakarta: Gave Media.

Fanny, A. M. (2013). Pengembangan Multimedia Interaktif Untuk Mata Pelajaran Ilmu Pengerahuan Sosial (IPS) Sekolah Dasar Kelas V. Jurnal Prima Edukasia, 1(1), 1-9.

Hana, U. S. (2016). Pengembangan Multimedia Interaktif Mapel IPA Untuk Siswa Kelas V Di SDN Kuwaron 1. E-Jurnal Prodi Teknologi Pendidikan, 5(5), 53-61.

Illahi, T. A. (2018). Pengembangan Multimedia Interaktif Pada Pembelajaran Materi Jenis-Jenis Pekerjaan Untuk Meningkatkan Kemampuan Berpikir Kritis. Jurnal Kajian Pendidikan dan Hasil Penelitian, Vol 4(3), 1-10.

Kuncahyono, \& Sudarmiatin. (2018). Pengembangan Multimedia Interaktif Pada Pembelajaran Tematik Indahnya Negeriku Untuk Siswa Kelas IV Sekolah Dasar. Jurnal Kajian Teori dan Praktik Kependidikan, 3(2), 156-163.

Lee, W. W., \& Owens, D. L. (2004). Multimedia -Based Instructional Design. San Fransisco: Pfeiffer.

Malik, S., \& Agarwal, A. (2012). Use of Multimedia as a New Educational Technology Tool-A Study. International Journal of Information and Education Technology, 2(5), 468-471.

Martin, F., Hoskins, O., Brooks, R., \& Bennett, T. (2013). Development Of An Interactive Multimedia Instructional Module. The Journal of Applied Instructional Design, 3(3), 5-17.

Munadi, Y. (2012). Media Pembelajaran. Jakarta: Gaung Persada. 
Nurul, A., \& Maris. (2000). Implementasi Kurikulum KTSP: Pembelajaran Tematik di Sekolah Dasar. Jurnal Inspirasi Pendidikan, 316-328.

Praherdiono, H., \& Adi, E. P. (2008). Panduan Praktikum Multimedia. Malang: FIP UM.

Prayogo, P. D. (2015). Pengembangan Multimedia Interaktif Tematik untuk Siswa Kelas IV SD Muhammadiyah Condongcatur. Yogyakarta: Fakultas Ilmu Pendidikan Universitas Negeri Yogyakarta.

Rachmadtullah, R., Ms, Z., \& Sumantri, M. S. (2018). Development of Computer-Based Interactive Multimedia : study on Learning in Elementary Education. International Journal of Engineering \& Technology, 7(4), 2051-2054. doi: 10.14419/ijet.v7i4.16384.

Rachmadtullah, R., Zulela, M., \& Sumantri, M. S. (2019). Computer-Based Interactive Multimedia: A Study On The Effectiveness Of Integrative Thematic Learning In Elementary Schools. Journal of Phyysics, 1-6. doi:10.1088/1742-6596/1175/1/012028.

Ramadhani, M., Gafari, M. F., \& Marice. (2019). Development of Interactive Learning Media on Material Writing Short Story Texts Based on Experience. Budapest International Research and Critics in Linguistics and Education (BirLE) Journal, 2(1), 91-102. DOI : https://doi.org/10.33258/birle.v2i1.189.

Ramadhani, R., \& Muhtadi, A. (2018). Development of Interactive Multimedia in Learning Islamic Education. International Journal of Multicultural and Multireligious Understanding, 5(6), 9-15. http://dx.doi.org/10.18415/ijmmu.v5i6.488.

Rosita, F. Y. (2015). Pengembangan Multimedia Interaktif Untuk Pembelajaran Berbicara Bagi Siswa Kelas IV Sekolah Dasar. Jurnal Inovasi Pembelajaran, 1(1), 25-37.

Sadiman, A. S. (2009). Media Pendidikan: Pengertian, Pengembangan dan Pemanfaatannya. Jakarta: PT. RajaGrafindo Persada.

Saifudin, M. F., Susilaningsih, \& Wedi, A. (2020). Pengembangan Multimedia Interaktif Materi Sumber Energi Untuk Memudahkan Belajar Siswa SD. Jurnal Kajian Teknologi Pendidikan, 3(1), 68-77.

Saputri, D. Y., Rukayah, \& Indriayu, M. (2018). Need Assessment of Interactive Multimedia Based on game in Elementary School: A Challenge into Learning in 21st Century. International Journal of Educational Research Review, 3(3), 1-8.

Setyosari, P., \& Sihkabuden. (2005). Media Pembelajaran. Malang: Elang Mas.

Susilo, O. S., Degeng, I. S., \& Susilaningsih. (2017). Pengembangan Multimedia Interaktif IPA Kelas V SD Pokok Bahasan Organ Tubuh Manusia dan Hewan. Edcomtech, 2(2), 161-166.

Syawaludin, A., Gunarhadi, \& Rintayati, P. (2019). Development of Augmented Reality-Based Interactive Multimedia to Improve Critical Thinking Skills in Science Learning. International Journal of Instruction, 12(4), 331-344.

Utami, S. (2016). Pengembangan Multimedia Pembelajaran Interaktif untuk Standar Kompetensi Melakukan Prosedur Administrasi Kelas X Program Keahlian Administrasi Perkantoran. Yogyakarta: Fakultas Ekonomi Universitas Negeri Yogyakarta.

Yusuf, M. F. (2017). Pengembangan Multimedia Interaktif IPA Materi Atmosfer Bumi Kelas VIII SMPN 3 Tulungagung. Edcomtech, 2(1), 37-40. 